\title{
Research on the Representation Method of Digital Image Art in the Era of Media Convergence
}

\author{
Ye Fenghua \\ Guangdong University of Technology,Guangzhou 51000, China
}

Keywords: Media convergence, Digital image, Expression technique, Rendering tool, 3D virtual.

\begin{abstract}
The media convergence has made the whole image industry become more active, and it brings more development space on the representation method of video art. Video production carries out cooperation with other media, making digital image art can show more incisively and vividly. The multimedia fusion method applies to the artistic expression of the image, in which the most commonly used artistic rendering tools are multimedia digital image processing software. This study takes studio video as an example, the arrow rain and wear water image art rendering effects are described. This paper summarizes three methods of digital image art effects, including computer image processing, image digital processing and image digital synthesis. Finally, this paper elaborates two kinds of new digital imaging technology of 3D virtual camera and virtual studio, which provides the valuable reference for the study of modern image art.
\end{abstract}

\section{Introduction}

The concept of media convergence was introduced into China in the early 21st century, and the evolution process of media convergence has three stages of interactive media, integrated media and media fusion [1-3]. After nearly a decade of research and exploration, China's media fusion has reached the fusion stage, but it is only a beginning in the stage of fusion $[4,5]$. The mutual fusion between the media makes the image industry become more active, but also brings more development space on the representation method of image art [6-8]. At the same time, the media makes the image from film to digital transition, but also realizes the multi way of image art, which provides a broad space for the development of image art.

\section{The Positive Influence of Media Convergence on Image Art}

Media convergence makes the whole image industry become more active, but also brings more development space on the representation method of image art [9-11]. Each link of industry is looking for image fusion method, and the positive impact is mainly reflected in the following two aspects [12-14]:

Image from film to digital transition. In the production of image, the use of nonlinear editing and digital synthesis technology can greatly improve the art performance effect of the image, but also creates a virtual space and realistic fusion scene [15]. In the process of image transportation, it omits the process of traditional image processing and printing, the image is saved the disk, optical disc, mobile hard disk in the form of digital files, or through the network and satellite transmission, its method not only saves the transport costs of the image, but also achieves the purpose of environmental protection. In the film, the elimination of film uses digital projection mode, and its artistic effect is more realistic and impact.

The multi way display of image art. As a result of multimedia fusion, video production must contact with other media cooperation, which can also make the digital image art show more incisively and vividly [16]. Internet provides a transmission platform for the video art, it not only can make the image have more art forms in addition to the hospital online mapping, but also can obtain the copyright benefit. The media can provide the advertising function for the image, in order to attract more image viewer. Smart phone is now most frequently used media, in which three net fusion functions make the image on the mobile phone play online. The image can be conducted propaganda 
through the portal website and mobile phone customer end, achieving the mutual benefit and win-win effect of image and other media.

\section{Digital Image Art Expression Method based on Multimedia Software}

The fusion of multimedia makes a variety of methods to apply to the performance of the image art, in which the multimedia digital image processing software is a very good image artistic rendering tools [17]. Digital image processing software is more, and this paper takes the Video Studio as an example.

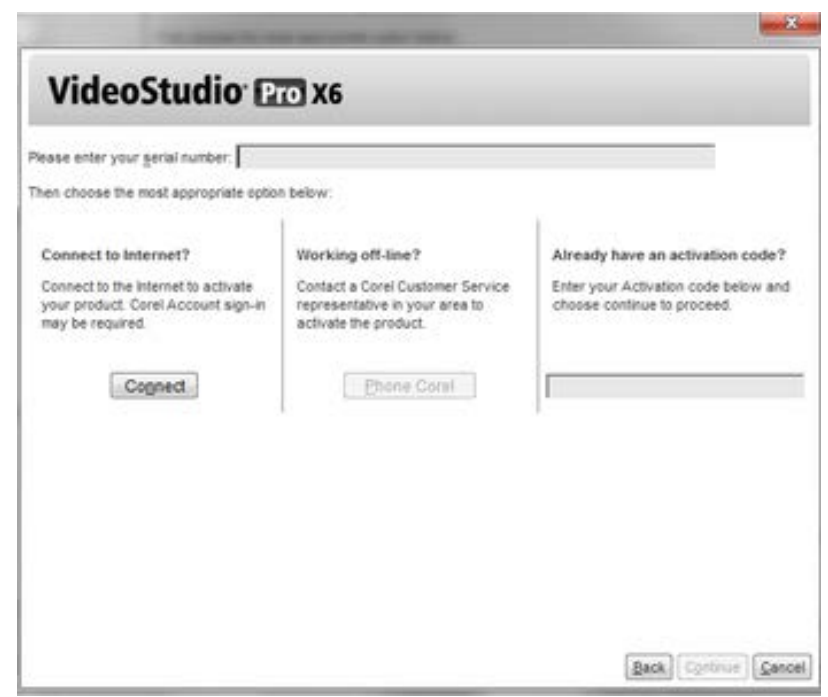

Fig. 1 Multimedia image processing software

For the rendering of the artistic effect in the image, we can use VideoStudio X6 to complete as shown in Figure 1. The X6 versions have more powerful video processing and the video can improve the network propagation velocity in the undistorted compression.
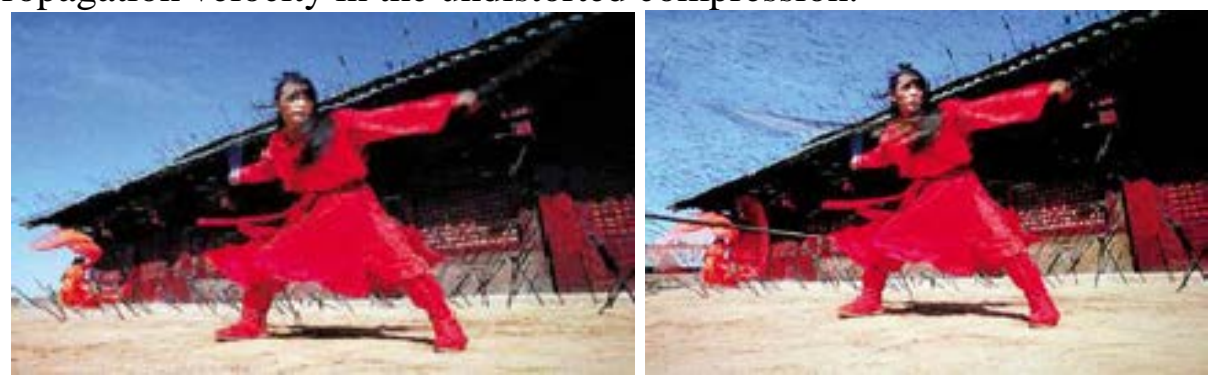

Fig. 2 The effect of the arrow rain image rendering

Figure 2 shows the rendering effect processed by the digital image processing software. Before rendering, the actual effect of the images is house and ground that have fixed a lot of arrows; after rendering, artistic effect is to fly the arrow, and let the actors in the air flying dance, to resist the flying arrows. The background of the actor's dancing and the arrow rain is synthesized through the digital multimedia processing software, and the background of the building and the blur effect of the actors are added through the software synthesis.
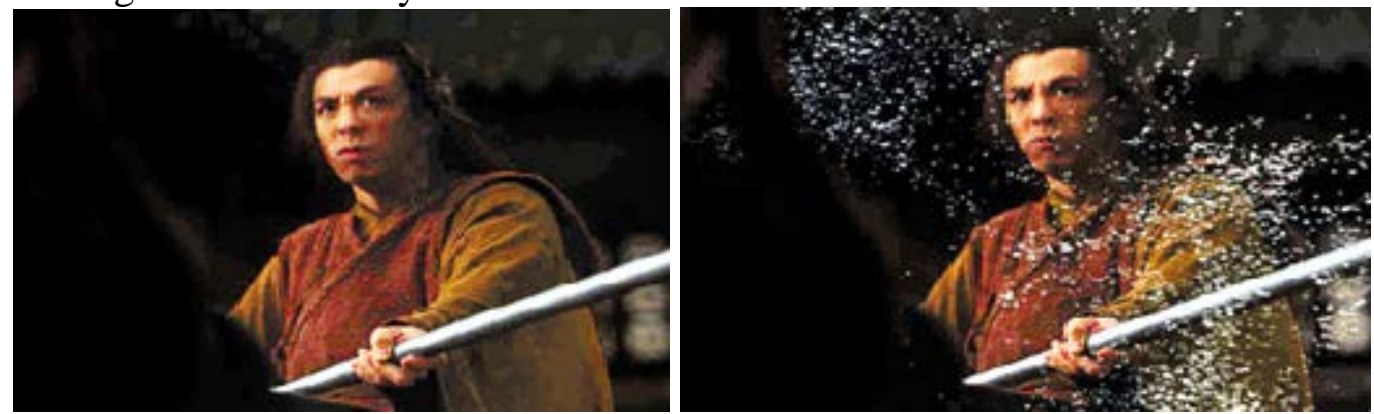

Fig. 3 Wear water drop image art rendering 
Figure 3 scene is three swords wear water scene in "hero" film, Wuming's sword speed is far faster than the rain falling speed when Wuming and Changkong duel, so as to see the sword through the path of the rain. But the artistic effect of the scene is not up to the actual shooting method, so it can be used in the production of digital image processing software for synthesis and rendering, in order to achieve the need to show the artistic effect.

\section{The Technical Means for the Realization of Digital Image Art}

Digital image art effects. The artistic effect of the image is a very important part of the production, especially in the movie making process. Special application is the most important, it gives the film more powerful vitality, so that the audience can get the unprecedented artistic experience, these are due to the multimedia fusion technology. Under the background of the media convergence era, the digital effects synthesis technology can be divided into three categories according to the functions, including computer image making, digital image processing and image digital synthesis.

(1) Computer image making

Computer video production is also known as computer graphics (CG) or computer imagery (CGI), it can will have no things become real picture, and using digital model can generate dynamic picture, so as to be beautiful and breathtaking shock art scene. Since the 1990s, the image technology generated by computer is a wide range of applications in video production, such as the "terminator" and "Avatar", incisively and vividly reflecting the role of the computer in the expression of image artistic effect.

(2) Digital image processing

Digital image processing uses the software on camera photographing picture or software generated screen processing, resulting in the new image of the film, including movie data repair, scene editing, and image editing and processing operations.

(3) Image digital synthesis

Image synthesis is a kind of medium fusion method of image art expression, and the method can handle a single picture as a composite picture, so as to embody the image art expression method of mixed material. The method of digital image synthesis mainly has the computer picking image technology, MotionControl, tracking, camera track reverse seeking, two machine depth identification system, Morph and so on. Multimedia digital image art performance objective is mainly reflected in two aspects, one is to create art scene when there are not art scene in the reality, which is a kind of artistic effect; another is to create television time and space on the basis of realism, to obtain the performance effect of the invisible art.

\section{The new methods of digital image art expression.}

(1) 3D virtual camera

3D virtual camera can be obtained extraordinary image artistic effect. "Avatar" with 3D + IMAX view effect has become the focus of global attention, it also lifts the CG technology revolution, and making the media convergence is more widely used in the performance of image art. 3D camera can get the scene to show the effect of more depth, its foreground and background will appear on different levels, this technology is the elimination of the previous mobile camera shooting method, so as to get a better dynamic stereo effect.

(2) Virtual studio

Virtual studio can make the image get stunning artistic effect, in the film "Avatar" shooting, the director uses a virtual studio to work with the camera, the reality and CG picture mapping together, so as to get the artistic effect of the shock. Virtual studio can be composed of multi digital cameras and build the performance capture technology platform, people will capture the spectral combination through the reflection of LED lamp to obtain the three-dimensional model, and then the data is mapped to the computer for further processing, to obtain the height fit really artistic effect. 


\section{Summary}

This paper describes the positive influence of media convergence on image art. Taking the video studio as an example, this paper describes the arrows and wears water images with artistic rendering effect, and summarizes three methods produced by the digital image art effects. Finally, this paper elaborates the two new digital imaging technologies, including 3D virtual camera and virtual studio. With the gradual maturity of network information technology and digital technology as well as with the rapid establishment of the fusion media terminal, image as one of the traditional art form must be reformed, to meet the market and audience's growing material and cultural needs.

\section{References}

[1] X.H. Tao. Analysis on the transformation of media industry structure under the background of media convergence. Contemporary communication, 2014, 4(13): 5-7.

[2] H. Yin. The movie industry memo in 2007. Movie literature, 2014, 2(5):36-37.

[3] S.Y. Wang. Study on the Internet movie concept and its characteristics. Contemporary communication, 2013, 11(4):90-91.

[4] X.R. Yang. Analysis on the Internet movie industry. Contemporary movies, 2013, 12(07):96-97.

[5] Y. He, W.Q. Wang, F. Xue. Research on massive data mining based on cloud computing. Computer technology and development, 2013, 23(2): 69-72.

[6] Y. Ding, Q.P. Yang, Y.M. Qian. Research on the data mining platform architecture and its key technologies based on cloud computing. ZTE technology, 2013, 19(1): 53-60.

[7] K. Li, Z. Chang. Design and implementation of parallel data mining system based on cloud computing. Micro computer information, 2014, 27(6): 121-123.

[8] G.L. Sun, H.L. Qi. The spam filtering based on online scheduling logic regression. Journal of Tsinghua University, 2013, 53(5): 734-740.

[9] B.T. Liu. Research on data mining algorithms based on rough sets. China western science and technology, 2013, 10(14): 11-12.

[10] Editorial Department of Journal of China Electronic Science Research Institute. The large data era. Journal of China Electronic Science Research Institute, 2013, 8(1): 27-31.

[11] S.R. Xu, B. Huang, W. Pu. Design and implementation of data mining platform based on MapReduce. Computer engineering and design, 2013, 34(2): 495-501.

[12] Q.S. Yu. Design and implementation on the constructing algorithm of the logical regression model based on the cloud platform. Science bulletin, 2013, 29(6): 137-139.

[13] J.X. Zhang, Z.M. Gu, C. Zheng. Overview of the research on cloud computing. Computer application research, 2013, 27(2): 429-433.

[13] L. Gao, Y.L. Wang. The humanization thinking on the design of graphics user software interface under the new media art. Modern decoration, 2013(9): 6-9.

[14] S.G. Wang. An improved image rotation algorithm. Journal of Shenyang Polytechnic University, 2014, 28(5): 22-25.

[15] Q. Yue, S. Feng. A systematic analysis on the computational performance of genetic algorithms. Journal of computers, 2013, 32(12): 2389-2392.

[16] J.H. Li, M. Li, L.H. Yuan. Pseudo parallel genetic algorithm based on clustering. Pattern recognition and artificial intelligence, 2013, 22(2): 188-194.

[17] J. Zhuang, Q.Y. Yang, H.F. Du. A efficient complex system genetic algorithm. Journal of software, 2013, 21(11): 2790-2801. 